\title{
Penerapan Sistem Modular untuk Konsep Grow dan Personalized pada Makeup Organizer Portable
}

\author{
Olivia Yolanda Simarmata dan Djoko Kuswanto \\ Departemen Desain Produk, Institut Teknologi Sepuluh Nopember (ITS) \\ e-mail:crewol@prodes.its.ac.id
}

\begin{abstract}
Abstrak-Modular merupakan sistem yang dibangun dari modular-modular yang dapat dibuat secara independen, mudah dikonfigurasi dan dapat dikonfigurasi ulang dalam sistem yang berbeda. Penerapan modular terhadap makeup organizer portable yang ditujukan untuk juru rias pemula, dimaksudkan untuk mempermudah seorang juru rias pemula untuk tetap menggunakan organizer yang sama hingga ia menjadi seorang juru rias professional. Makeup organizer portable yang biasanya dipasarkan di Indonesia merupakan makeup organizer case yang memiliki fitur banyak pada produknya, namun memiliki penyimpanan yang kurang. Akibatnya, juru rias sering mengganti makeup organizer yang ia punya dan mencoba mengganti/menambahkan organizer yang ia punya. Maka dari itu, penggunaan sistem modular pada makeup organizer portable akan menjadi alternatif baru untuk seorang juru rias pemula yang ada di Indonesia.
\end{abstract}

Kata Kunci-Juru Rias, modular, organizer, grow, personalized.

\section{PENDAHULUAN}

$\mathbf{J}^{\mathrm{m}}$ URU RIAS adalah seorang professional yang bertugas untuk mengubah atau meningkatkan penampilan seseorang dengan riasan. Semua orang memulai karirnya tentu berawal sebagai pemula di bidangnya. Begitu juga dengan seorang juru rias. Juru rias akan memulai karirnya sebagai pemula, namun semakin lama ia menggeluti pekerjaannya, semakin banyak jenis riasan yang akan dia kuasai, yang juga berefek pada barang- barang yang dibutuhkan oleh juru rias akan semakin kompleks dan bervariasi. Dikarenakan juru rias adalah profesi yang sangat kompetitif[1], seorang juru rias harus mampu meningkatkan kinerja dengan meningkatkan keterampilannya dan juga aksesoris yang menunjang karirnya.

Meningkatnya peminat juru rias di masyarakat, memunculkan peminat baru pada pekerjaan[2]. Tentunya peningkatan minat pada juru rias juga mempengaruhi peningkatan minat pada aksesoris penunjuang juru rias. Salah satunya ialah organizer. Organizer dibutuhkan oleh seorang juru rias dikarenakan banyaknya kebutuhan alat dan bahan untuk merias seseorang, sehingga penyimpanan dan penataan untuk alat dan bahan merias bisa dijadikan sebuah organizer yang dapat membantu juru rias membawa barang-barangnya ke tempat klien. Tak hanya itu, kebutuhan seorang juru rias selain organizer ialah lampu, kamera, dan sebagainya tergantung kebutuhan dari juru rias tersebut. Hal ini menunjukkan jika seorang juru rias membawa banyak barang untuk keperluan meriasnya.

Keperluan aksesoris penunjang juru rias yang tidak murah membuat seorang juru rias harus menyiapkan modal yang

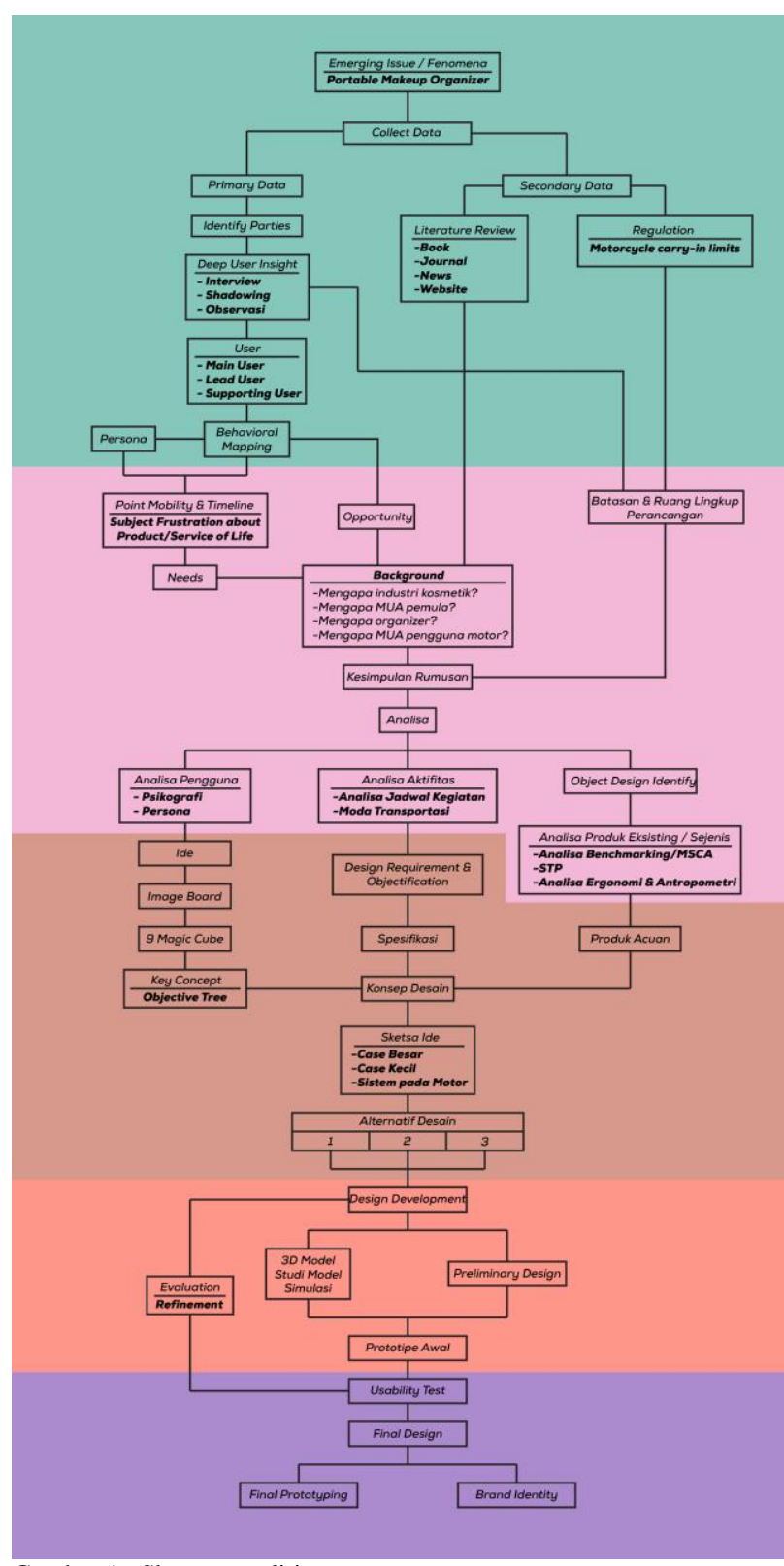

Gambar 1. Skema penelitian.

cukup besar untuk memulai karirnya. Maka dari itu, seorang juru rias diharapkan bisa memilih keperluannya dengan tepat, baik secara kualitas maupun harga. Karena dengan kualitas yang baik, barang tersebut akan bertahan hingga bertahuntahun dan membuat juru rias tidak perlu membeli lagi beberapa kali yang menguras modal.

Salah satu aksesoris yang digunakan oleh seorang juru rias adalah makeup organizer. Makeup organizer yang dimiliki oleh seorang juru rias bergantian sesuai dengan kebutuhan 


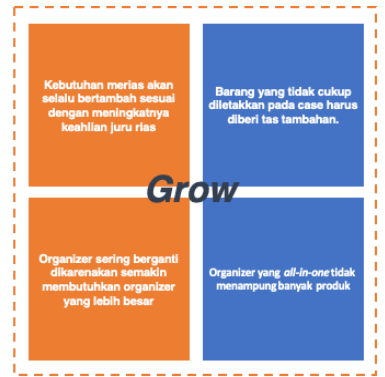

Gambar 2. Kegiatan-kegiatan yang menghasilkan konsep Grow.

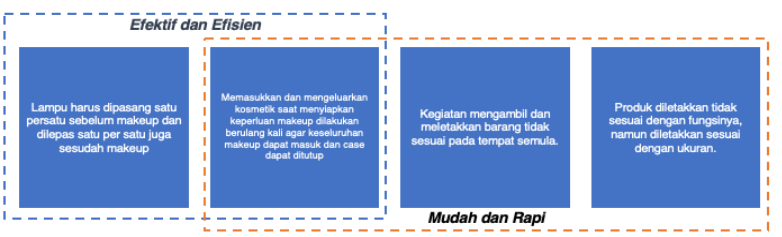

Gambar 3. Kegiatan-kegiatan yang menghasilkan konsep efektif dan efisien, juga mudah dan rapi.

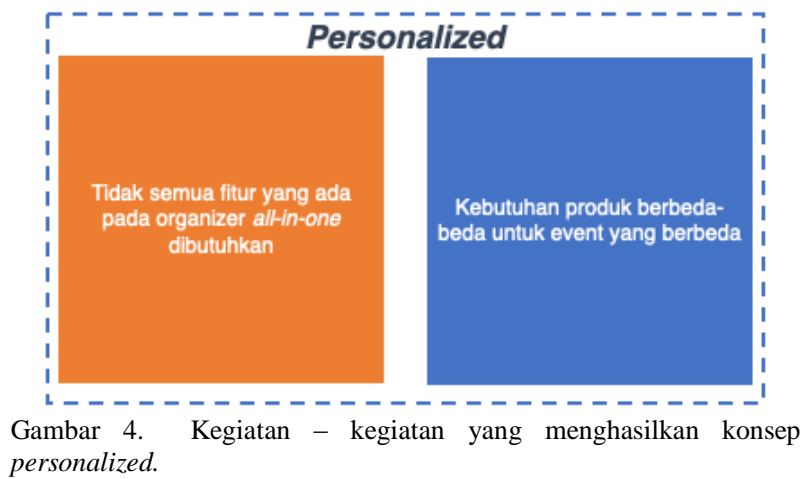

klien dan juru rias tersebut. Dan kebutuhan mereka tentu berbeda-beda. Seorang juru rias diharapkan mampu mengatur isi yang ada di dalam makeup organizer-nya sehingga juru rias tidak membawa barang yang tidak terlalu diperlukan. Hal ini menunjukkan seorang juru rias membutuhkan organizer yang bisa disesuaikan dengan kebutuhannya.

Modular merupakan salah satu sistem dimana menciptakan pola desain yang bisa berdiri sendiri, mudah dikonfigurasi, dan di re-konfigurasi ke dalam sistem yang berbeda[3]. Modular terdiri dari modul-modul yang bisa dikembangkan sendiri, dan/atau kemudian bisa digabung bersama[4]. Ini merupakan menjadi peluang bagi desainer untuk merancang sebuah produk yang mampu digunakan jangka panjang namun tetap bisa dijangkau oleh user ketika ia masih berada di posisi pemula, dengan sistem modular

\section{METODE PENELITIAN}

\section{A. Studi Literatur}

Metode ini dilakukan dengan mengumpulkan data pustaka melalui jurnal, artikel, atau buku, untuk mencari teori atau studi yang telah digambarkan dapat dilihat pada Gambar 1.

\section{B. Benchmarking}

Metode ini merupakan pengumpulan data berdasarkan produk eksisting atau kompetitor terkait. Kemudian dilakukan analisa untuk mempertimbangkan produk selanjutnya.
Tabel 1.

Pembagian Modul

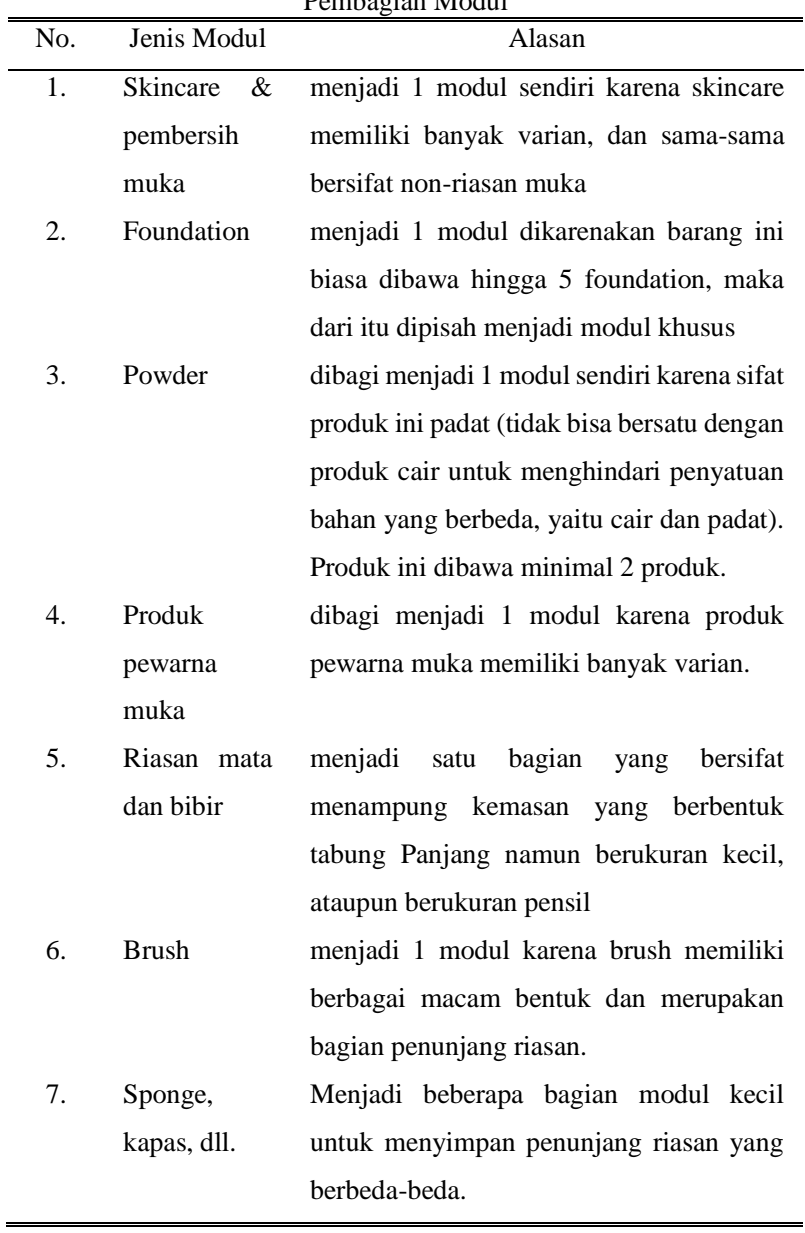

\section{Skema Penelitian}

Skema penelitian menjelaskan secara garis besar penelitian ini dilakukan, dengan menggunakan proses design thinking, yaitu emphatize, define, ideation, prototype, dan test.

\section{HASIL RISET DAN PEMBAHASAN}

\section{A. Affinitiy Diagram}

Merupakan studi yang dilakukan untuk menemukan apa yang menjadi kebutuhan dari pengguna portable make-up organizer yang datanya didapat dari masalah yang ditemukan dengan metode shadowing dan deep interview. Dari data yang didapat, kemudian dilakukan pengelompokan masalah sehingga didapatkan pertimbangan untuk mendesain.

\section{1) Grow}

Produk diharapkan dapat bertumbuh seiring barang dari juru rias selalu bertambah, sehingga produk dapat selalu digunakan hingga juru rias sudah semakin professional dapat dilihat pada Gambar 2.

\section{2) Efektif dan Efisien}

Efektif dan efisien disini mewakilkan produk dapat digunakan dengan maximal dan mencapai tujuan dari produk tersebut.

\section{3) Mudah dan Rapi}

roduk diharapkan mampu digunakan dengan mudah dan tersusun dengan rapi sebagaimana yang diharapkan sebagi fungsi dari organizer. 


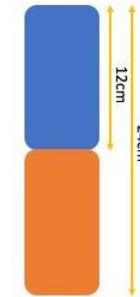

Foundation

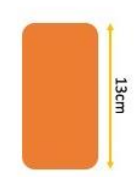

Primer

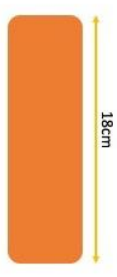

Brush

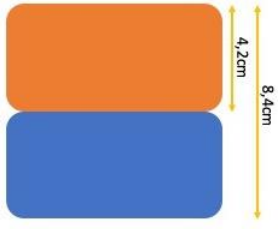

Powder
Gambar 5. Ukuran tertinggi dari produk-produk yang mempengaruhi tinggi modul.

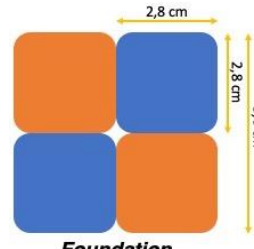

Foundation

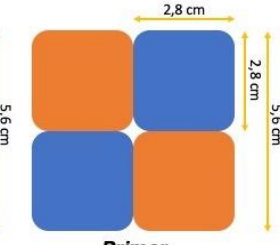

Primer

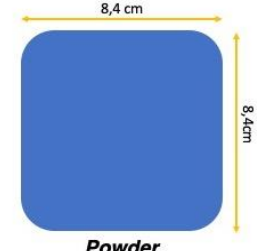

Powder
Gambar 6. Ukuran panjang dan lebar dari komponen terbesar yang dibawa oleh juru rias.

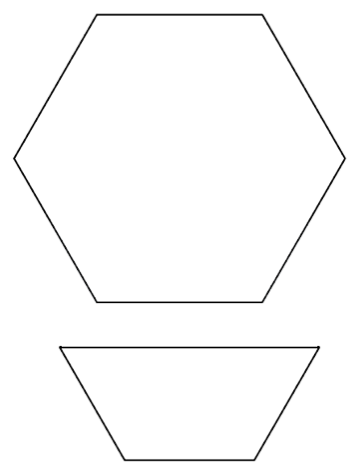

Gambar 7. Bentuk modul yang dihasilkan.
Purple

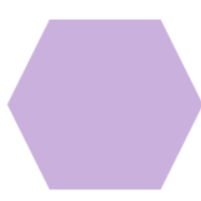

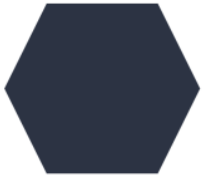

Black

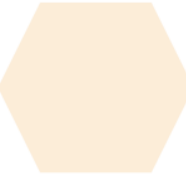

Beige
Gambar 8. Pembagian warna pada modul-modul.

\section{4) Personalized}

Produk yang dihasilkan diharapkan dapat mengikuti kebutuhan dari si pengguna, yaitu kebutuhan dari juru rias itu sendiri, yang disesuaikan dengan kebutuhan dari klien dari user dapat dilihat pada Gambar 3.

Dari hasil pembahasan affinitiy diagram, sistem modular sangat mendukung untuk tercapainya hasil dari affinity diagram dapat dilihat pada Gambar 4.

\section{B. Analisis Pembagian Modul}

Pembagian modul didasarkan pada (yang diurutkan berdasarkan prioritas): fungsi, sifat wujud dari produk, dan ukuran dari produk tersebut. Sifat wujud dari produk mempengaruhi kemasan dari produk tersebut. Dikarenakan aspek utama dari sebuah kemasan yaitu tipe wadah, kesesuaian, fungsi, dan proteksi dari produk dapat dilihat pada Tabel 1[1].

Untuk produk-produk yang memiliki ukuran yang sangat berbeda dan berjumlah hanya satuan, diberikan partisi pada tas sehingga lebih menghemat space pada tas.
Tabel 3.

Modul-Modul Akhir

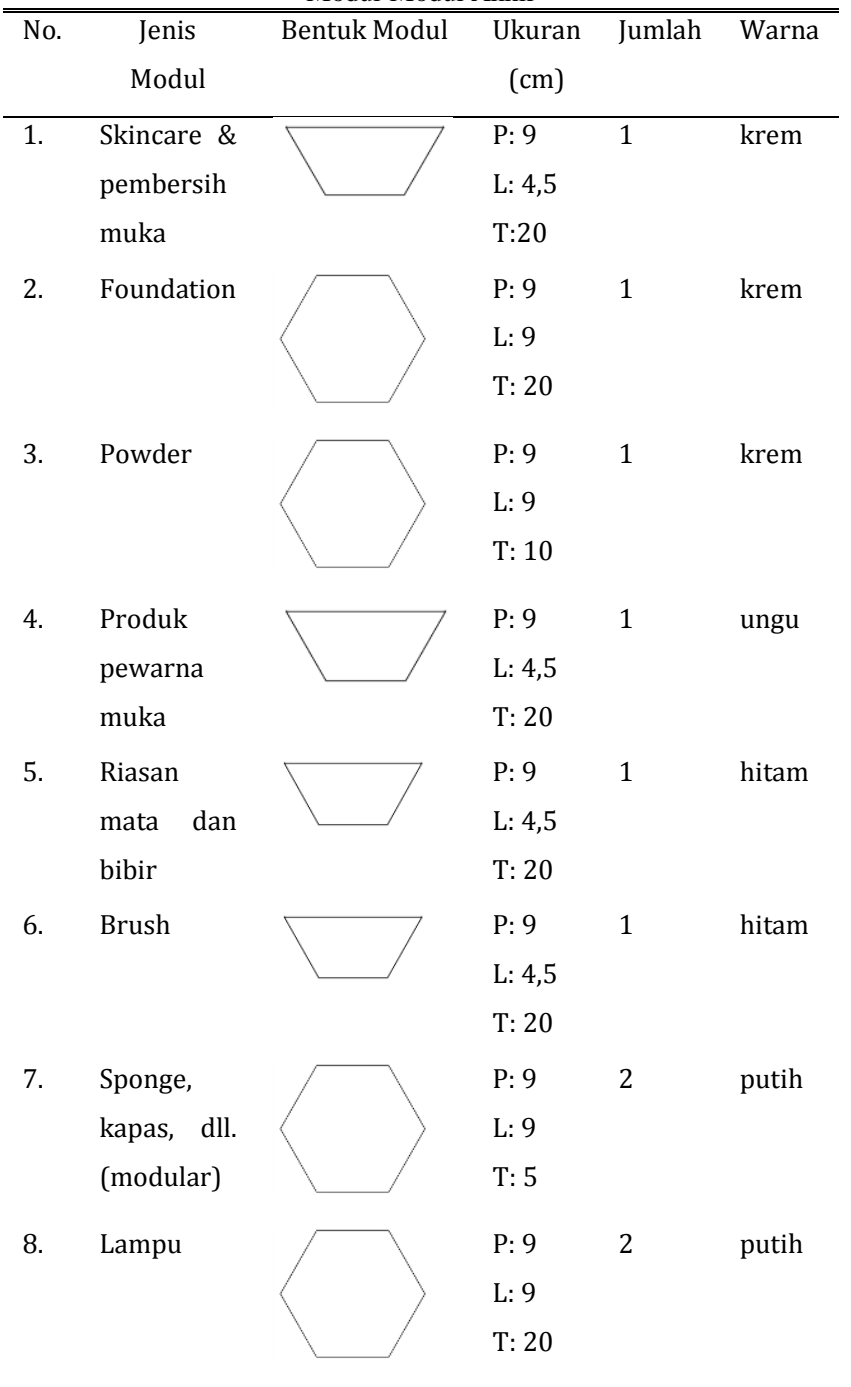

\section{Analisis Ukuran}

Analisis ukuran ditujukan untuk menemukan ukuran modul-modul yang akan digunakan. Analisis ukuran yang diambil berdasarkan ukuran komponen-komponen terbesar dari keperluan juru rias, dimana untuk ukuran panjang dan lebar diambil dari komponen yang memiliki ukuran terbesar untuk panjang dan lebarnya, yaitu foundation, primer, dan powder. Sedangkan untuk ukuran tinggi didapatkan dari komponen foundation, primer, dan brush, dimana komponen-komponen tersebut adalah komponen tertinggi dari kebutuhan juru rias. Gambar diatas merupakan ukuran dari per komponen kebutuhan juru rias.

Didapatkan ukuran terbesar dari komponen makeup yang dibutuhkan juru rias, untuk panjang dan lebar didapatkan 8,4 $\mathrm{cm}$ dan tinggi $18 \mathrm{~cm}$. pembulatan keatas dilakukan bertujuan untuk memberikan sedikit ruang kosong agar produk yang ada di dalam modul tidak sulit ketika dikeluarkan ataupun dimasukkan ke dalam modul dapat dilihat pada Gambar 5.

Ukuran modul dibagi menjadi beberapa ukuran yang berbeda-beda dikarenakan fungsi yang berbeda beda juga. Namun agar tetap ada fungsi dari modular, ukuran yang besar harus memiliki kelipatan dengan ukuran yang paling kecil.

1) Tinggi Modul

Pada ukuran tinggi dari bedak (powder), bisa dilihat pada gambar 5 yang menunjukkan ukuran jika beda ditumpuk 2 
Tabel 2.

Penilaian Bentuk Modul

No.

adalah 8,4 cm. Jika dibulatkan ke atas, akan didapatkan ukuran $10 \mathrm{~cm}$. Tinggi ini didapatkan untuk modul kecil dapat dilihat pada Gambar 6.

Lalu untuk ukuran dari tinggi yang besar didapatkan dari produk yang berukuran besar juga, yaitu pada foundation dengan tinggi $24 \mathrm{~cm}$ jika ditumpuk 2 dan brush memiliki tinggi berukuran $18 \mathrm{~cm}$. Dari 2 ukuran tinggi tersebut, dan dipertimbangkan dengan tinggi modul kecil, didapatkan ukuran $20 \mathrm{~cm}$, dimana tidak akan membuat modul dengan brush memiliki jarak yang terlalu kecil juga foundation yang bisa menyesuaikan dengan tinggi yang ada.

\section{2) Panjang dan Lebar Modul}

Panjang dan lebar modul yang didapatkan berdasarkan ukuran terbesar yang didapatkan dari pembahasan di awal ialah $8,4 \mathrm{~cm}$ yang dibulatkan ke atas menjadi $9 \mathrm{~cm}$. Pembulatan ke atas dimaksudkan agar ada sedikit ruang yang ada di dalam modul sehingga tidak kesulitan ketika mengambil dan menaruh barang. Seperti yang dibahas di beberapa paragraf di atas, ukuran besar harus memiliki kelipatan dengan ukuran kecil. Ukuran $9 \mathrm{~cm}$ memiliki kelipatan yang lebih kecil yaitu 4,5 cm. Jadi untuk modul yang lebih kecil, panjang atau lebarnya bisa menggunakan ukuran 4,5 cm dapat dilihat pada Tabel 2.

\section{Analisis Bentuk Modul}

Untuk mencapai penerapan sistem modular, tentu bentuk modul diperlukan untuk mencapai modular yang baik. Berikut perbandingan beberapa bentuk sederhana yang menjadi bentuk modul.

Pada Tabel 2, dimasukkan nomor yang diurutkan paling bisa mencapai nilai yang diharapkan (4) hingga yang paling tidak mencapai nilai yang diharapkan (1). Nilai yang didapatkan adalah sebagai berikut:

1. Hexagon : 12

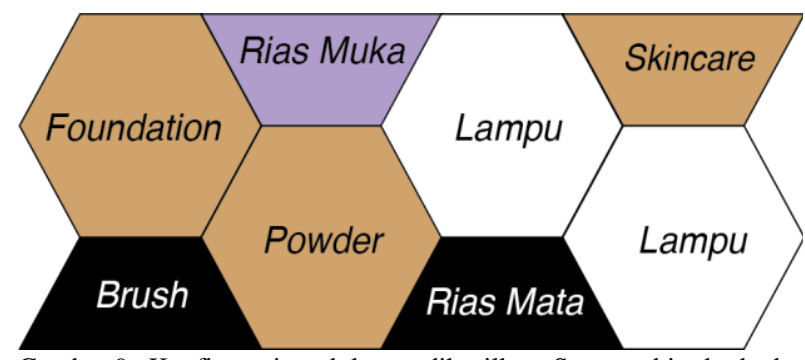

Gambar 9. Konfigurasi modul yang dihasilkan. Susunan bisa berbedabeda.

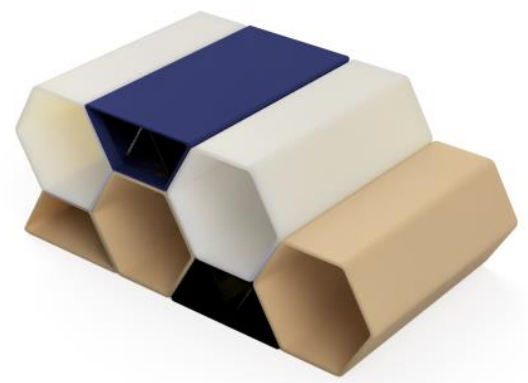

Gambar 10. Bentuk konfigurasi dalam 3D

2. Lingkaran : 4

3. Segitiga $: 8$

4. Segiempat : 7

Kebutuhan untuk merias memiliki bentuk yang berbedabeda, namun ada 2 bentuk yang paling sering dipakai sebagai bentuk kemasan dari kebutuhan perias, yaitu kotak dan lingkaran. Hexagon memang merupakan salah satu bentuk yang paling optimal untuk membuat modul pada modular. Hexagon mampu menampung bentuk-bentuk yang berbedabeda, namun memiliki jarak yang sedikit antara modul dan isinya. Maka dari itu, pada riset kali ini akan dilakukan modul dengan bentuk hexagon dapat dilihat pada Gambar 7.

Bentuk modul yang berbeda-beda namun menerapkan bentuk hexagon dan sistem modular, maka dari bentuk hexagon, didapatkan 2 bentuk, yaitu hexagon dan trapesium sama kaki, dimana trapesium sama kaki merupakan setengah bagian dari hexagon dapat dilihat pada Gambar 8 .

\section{E. Analisis Warna}

Analisis warna dilakukan untuk menentukan warna pada modul. Penentuan warna ini dimaksudkan agar adanya kemudahan pada pengguna terhadap produk ini. Dikarenakan modular memiliki bentuk yang sama pada bagian luarnya, maka, bentuk tidak akan membantu pengguna dalam mengenali produk apa yang dibawa oleh suatu modul. Maka dari itu, warna akan

Modul dibagi beberapa warna yang disesuaikan dengan isi dari modul-modulnya. Sebagaimana dibahas pada pembagian modul di atas, ada modul yang menyimpan produk yang berguna sebagai pondasi muka, riasan muka, riasan mata, atau riasan bibir.

Pembagian warna dibagi menjadi 3 warna, yaitu:

1. Ungu : difungsikan untuk modul yang bersifat sebagai riasan berwarna

2. Hitam : difungsikan untuk modul yang bersifat sebagai aksesoris atau riasan yang berwarna hitam (riasan mata).

3. Krem : warna ini ditujukan untuk modul yang menyimpan pondasi muka. 


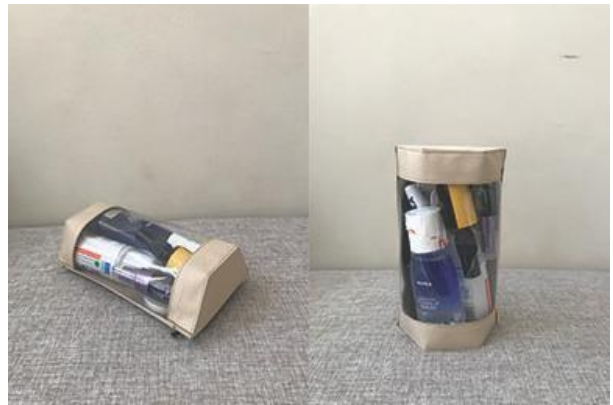

Gambar 11. Modul Skincare.

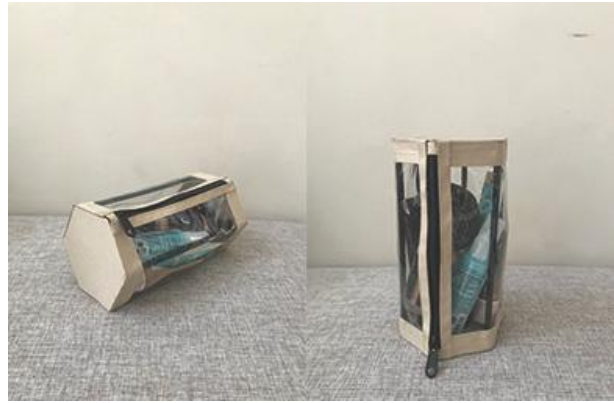

Gambar 12. Modul Foundation.

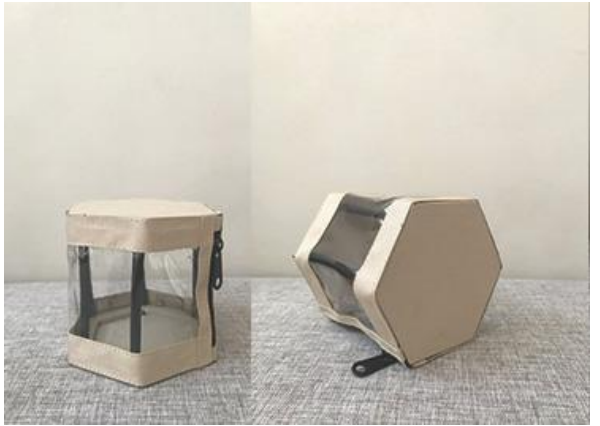

Gambar 13. Modul Powder.

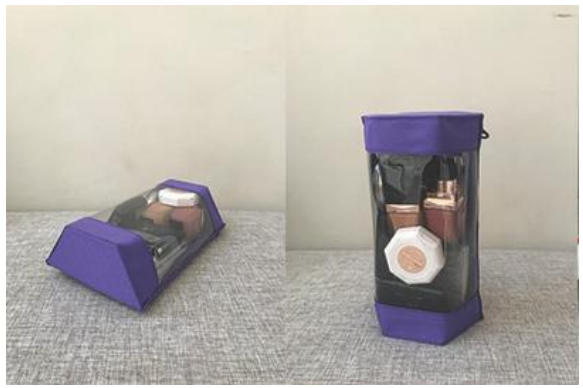

Gambar 14. Modul Rias Muka.

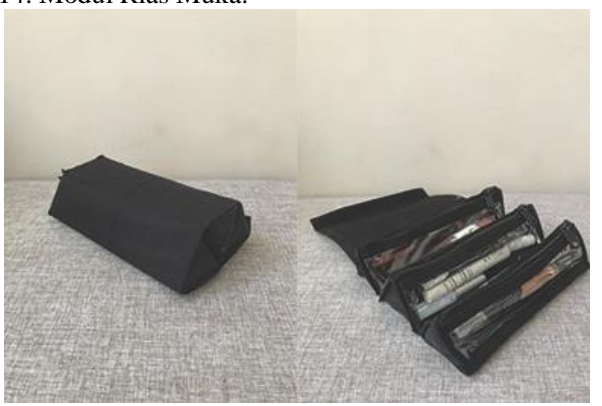

Gambar 15. Modul Rias Mata dan Bibir.

\section{F. Lampu}

Lampu merupakan salah satu aksesoris penting yang dibutuhkan oleh juru rias. Sebagaimana lampu bermakna sebagai alat untuk menerangi[1], lampu pada juru rias membantu untuk menajamkan hasil makeup ketika dilihat dengan mata secara langsung. Lampu dibuat untuk berbentuk hexagon juga sehingga bisa membentuk modular dengan modul-modul organizer.

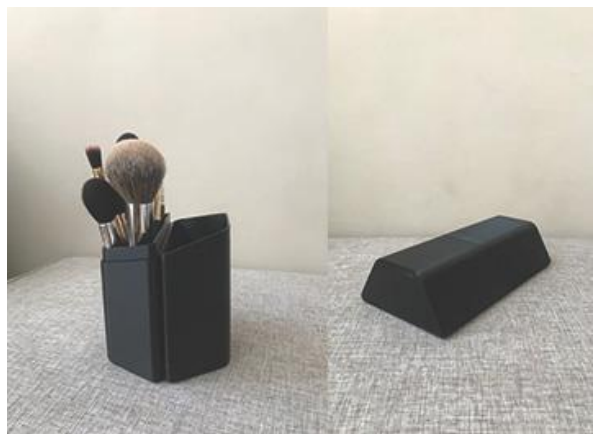

Gambar 16. Modul Brush

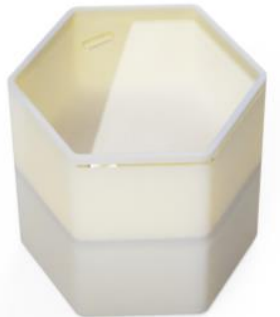

Gambar 17. Modul Aksesoris Tambahan

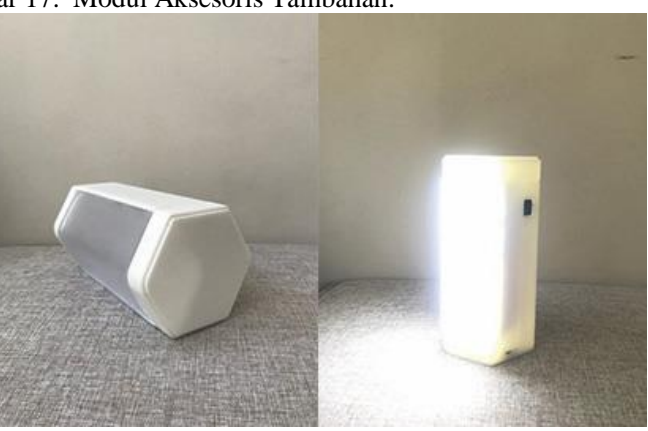

Gambar 18. Modul Lampu.

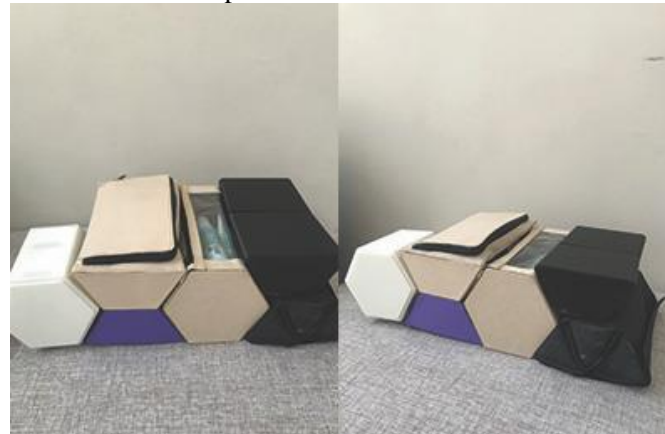

Gambar 19. Konfigurasi Akhir.

\section{G. Konfigurasi Modul}

Konfigurasi adalah bagaimana setiap modul dirangkai menjadi satu kesatuan. Berikut adalah bentuk dari konfigurasi untuk modul-modul yang telah dihasilkan dari analisisanalisis di atas dapat dilihat pada Tabel 3 dan Gambar 9 - 10.

\section{H. Hasil Akhir Modul}

Hasil akhir dari modul ini terdiri dari softcase dan hardcase yang disesuaikan dengan fungsi dari bagian-bagian modula yang ada. Berikut adalah hasil dari modul-modul pada penelitian ini yang dapat dilihat pada Gambar $11-18$.

1. Skincare

2. Foundation

3. Powder

4. Rias Muka

5. Rias Mata dan Bibir

6. Brush

7. Aksesoris Tambahan (Sponge, dll)

8. Lampu 
Hasil akhir konfigurasinya dapat dilihat pada Gambar 19.

\section{KESIMPULAN/RINGKASAN}

Setelah melakukan observasi, studi, dan analisis, kesimpulan dari penelitian ini ditunjukkan untk menjawab permasalahan yang telah dijabarkan.

1. Penerapan modular dapat mencapai produk dengan konsep grow sehingga juru rias dapat terus menerus menggunakan organizer yang ia miliki ketika ia masih pemula hingga ia menjadi seorang professional.

2. Penerapan modular mampu menjawab harapan dari penelitian ini, yaitu personalized, dimana juru rias dapat menukar-nukar susunan modul-modul yang ada di dalam tas utamanya.

Saran dari penelitian ini adalah perlu adanya eksplorasi pola potong sehingga menemukan bentuk yang lebih maximal.

\section{DAFTAR PUSTAKA}

[1] V. J.-R. Kehoe, The Technique of the Professional Make-Up Artist, Revised. Oxford, United Kingdom: Taylor \& Francis Ltd, 1995.

[2] S. Place and B. R. Madry, The art and science of professional makeup. Bronx, New York: Milady Pub. Co., 1989

[3] C.-C. Huang and A. Kusiak, "Modularity in design of products and systems," IEEE Trans. Syst. Man, Cybern. - Part A Syst. Humans, vol. 28, no. 1, pp. 66-77, 1998.

[4] H. Lautenschläger, "Jars, tubes, dispensers etc - cosmetic packaging," Beauty Forum, vol. 10, pp. 48-51, 2011. 